\title{
Substance Use Disorder Treatment Availability Among States Considering Medicaid Work Requirements
}

\author{
Paul J. Christine, MD, $P h D^{7}$ (1) and Renuka Tipirneni, MD, MSc $c^{2,3}$ \\ 'Department of Internal Medicine, University of Michigan, Ann Arbor, MI, USA; 2 Department of Internal Medicine, Division of General Medicine, \\ University of Michigan, Ann Arbor, MI, USA; ${ }^{3}$ Institute for Healthcare Policy and Innovation, University of Michigan, Ann Arbor, MI, USA.
}

J Gen Intern Med 35(7):2234-6

DOI: $10.1007 / \mathrm{s} 11606-019-05623-1$

(c) Society of General Internal Medicine 2020

\section{INTRODUCTION}

In 2018, the Department of Health and Human Services began inviting state Medicaid reforms to "increase employment and community engagement" among enrollees by requiring work or similar activities as a condition of Medicaid eligibility. As of September 2019, seventeen states have applied for section 1115 Medicaid work requirement waivers, nine of which have been approved (with three currently on hold by federal courts). ${ }^{1}$ Such programs oblige individuals to complete a specified number of work, job training, job search, or community service hours to maintain Medicaid coverage, with exemptions for pregnant and disabled individuals.

Many work requirement proposals also make exceptions for individuals with substance use disorders (SUD), though this is often conditional on participation in a SUD treatment program. ${ }^{2}$ Given the high prevalence of SUD within the Medicaid population, ${ }^{3}$ the availability of SUD treatment may be crucial to maintenance of Medicaid eligibility for individuals in states pursuing work requirements. We sought to quantify the availability of SUD treatment resources in states with and without Medicaid work requirements.

\section{METHODS}

We compared SUD prevalence, all overdose deaths, opioid overdose deaths, and SUD treatment availability across work requirement categories (approved, pending, or no work requirement in the state). Data sources were as follows: work requirement policies (Kaiser Family Foundation, ${ }^{1}$ National Academy for State Health Policy ${ }^{2}$ ); SUD prevalence (National Survey on Drug Use and Health); opioid overdose deaths (CDC WONDER); state population (US Census); SUD treatment facility data, including acceptance of Medicaid payment, offering opioid treatment program, and offering opioid maintenance therapy (OMT) (National Survey of Substance Abuse

Received December 1, 2019

Accepted December 13, 2019

Published online January 8, 2020
Treatment Services); number of licensed prescribers with waiver to prescribe buprenorphine for opioid use disorder (Substance Abuse and Mental Health Service Administration [SAMHSA] provider locator). Analyses were conducted at the state level using SAS (version 9.4) in September 2019, with $t$ tests or Wilcoxon tests as appropriate. All data (except work requirement status) pertained to 2017 . The study was deemed exempt from approval by the IRB.

\section{RESULTS}

Prevalence of SUD was similar across states with and without Medicaid work requirements (Table 1). However, states with approved Medicaid work requirement waivers had a higher burden of both overall and opioid-related overdose deaths, compared with states with pending or no work requirements.

Availability of SUD treatment facilities was similar across work requirement categories, and a majority of facilities accepted Medicaid payment irrespective of work requirement status (Table 2). For opioids, the median proportion of SUD treatment facilities with a formal opioid treatment program or offering OMT was low across all states, though was generally lower among states with work requirements.

Similarly, when scaled by the burden of opioid-related deaths in each state, states with work requirements had lower numbers of treatment facilities offering opioid treatment programs or OMT (Table 2). The median number of clinicians waivered to prescribe buprenorphine was also lower in states with work requirements compared with states without requirements.

\section{DISCUSSION}

We found that states with approved Medicaid work requirements generally have both a higher burden of drug overdose deaths and proportionately fewer treatment resources, compared with states without work requirement waivers. Particularly for opioid use disorder, states with approved or pending work requirements had fewer treatment facilities providing recommended treatments and fewer clinicians waivered to prescribe buprenorphine. Study limitations include limited ability to distinguish between treatment resource availability and true access to care, and known incomplete data on waivered clinicians from SAMHSA. ${ }^{4}$ 
Table 1 Characteristics of Substance Use Disorder Policies and Prevalence in States with Approved, Pending, and no Medicaid Work Requirements

\begin{tabular}{|c|c|c|c|c|c|}
\hline $\begin{array}{l}\text { Medicaid work } \\
\text { requirement waiver } \\
\text { status }\end{array}$ & $\begin{array}{l}\text { SUD treatment as } \\
\text { qualifying activity }\end{array}$ & $\begin{array}{l}\text { SUD as exemption } \\
\text { to work } \\
\text { requirement }\end{array}$ & $\begin{array}{l}\text { SUD prevalence (\% of } \\
\text { state population } \geq \\
18 \text { years old) }\end{array}$ & $\begin{array}{l}\text { All overdose deaths } \\
\text { per } 100,000 \\
\text { population }\end{array}$ & $\begin{array}{l}\text { Opioid overdose } \\
\text { deaths per } 100,000 \\
\text { population }\end{array}$ \\
\hline $\begin{array}{l}\text { Approved work } \\
\text { requirement }\end{array}$ & & & $7.9(0.16)$ & $27.4(3.0)$ & $20.3(3.2)$ \\
\hline Arizona ${ }^{\dagger}$ & No & Yes & 7.7 & 21.8 & 13.2 \\
\hline Arkansas & No & Yes & 7.7 & 14.8 & 6.3 \\
\hline Indiana $^{\dagger}$ & $\mathrm{Yes}^{\S}$ & Yes & 7.6 & $\begin{array}{l}14.0 \\
27.8\end{array}$ & $\begin{array}{l}0.3 \\
17.6\end{array}$ \\
\hline Kentucky & Yes & No & 7.5 & 35.2 & 26.0 \\
\hline Michigan & Yes & No & 7.9 & 27.0 & 20.4 \\
\hline New Hampshire & Yes & Yes" & 8.7 & 34.8 & $\begin{array}{l}20.4 \\
31.6\end{array}$ \\
\hline Ohio & No & Yes & 8.1 & 43.8 & 36.8 \\
\hline Utah & No & Yes & 7.2 & 21.0 & 14.7 \\
\hline Wisconsin ${ }^{\dagger}$ & No & Yes & 8.5 & 20.3 & 16.0 \\
\hline $\begin{array}{l}\text { Pending work } \\
\text { requirement }\end{array}$ & & & $7.8(0.4)$ & $16.6(2.1)$ & $10.1(2.0)$ \\
\hline Alabama & No & No & 6.9 & 17.1 & 8.7 \\
\hline Mississippi & Yes & Yes & 6.8 & 11.9 & 6.2 \\
\hline Montana & Yes & No & 9.2 & 11.3 & 3.6 \\
\hline Oklahoma & No & Yes & 7.8 & 19.7 & 9.9 \\
\hline South Carolina & No & Yes $^{\text {gl }}$ & 7.9 & 20.1 & 14.9 \\
\hline South Dakota & Yes $^{\#}$ & No & 9.6 & 8.4 & 4.0 \\
\hline Tennessee & No & Yes $^{* *}$ & 6.9 & 26.4 & 18.9 \\
\hline Virginia & No & Yes & 7.8 & 17.8 & 14.7 \\
\hline No work requirement ${ }^{*}$ & & & $8.2(0.2)$ & $22.5(1.9)$ & $15.8(1.8)$ \\
\hline
\end{tabular}

SUD, substance use disorder

*Values in rows represent means (standard errors) pooling all states together within a work requirement category

†tates that have suspended or postponed plans to implement Medicaid work requirements

tStates with Medicaid work requirements that are currently on hold by federal courts

SIndiana's Gateway to Work program encourages enrollees with SUDs to seek treatment, which will then qualify for exemption

"New Hampshire's waiver considers SUD treatment an exemption only for those participating in a state-certified drug court program

"South Carolina's waiver requires participation in a Medicaid-covered treatment program

"South Dakota's waiver lists treatment for "behavioral health" as a qualifying activity, though it is unclear if this will specifically include individuals with SUD

** Tennessee's waiver specifies that individuals must be engaged in inpatient, residential, or intensive outpatient treatment programs to qualify for exemptions

Table 2 Substance Use Disorder Treatment Availability Among States with Approved, Pending, or no Medicaid Work Requirement Waivers

\begin{tabular}{|c|c|c|c|c|}
\hline \multirow[t]{2}{*}{ Measure of SUD treatment availability } & \multicolumn{3}{|l|}{ Work requirement category } & \multirow{2}{*}{$\begin{array}{l}P \\
\text { value }^{\dagger}\end{array}$} \\
\hline & $\begin{array}{l}\text { Approved work } \\
\text { requirement }(n=9 \text { states })\end{array}$ & $\begin{array}{l}\text { Pending work } \\
\text { requirement }(n=8 \\
\text { states) }\end{array}$ & $\begin{array}{l}\text { No work requirement } \\
(n=34 \text { states })\end{array}$ & \\
\hline $\begin{array}{l}\text { Proportion of SUD treatment facilities accepting } \\
\text { Medicaid payment }\end{array}$ & $66.5(5.5)$ & $66.3(2.6)$ & $70.7(3.1)$ & 0.32 \\
\hline $\begin{array}{l}\text { SUD treatment facilities per } 100 \text { drug overdose } \\
\text { deaths }\end{array}$ & $22.3(6.7)$ & $20.0(28.5)$ & $22.1(33.4)$ & 0.41 \\
\hline $\begin{array}{l}\text { Proportion of SUD treatment facilities with opioid } \\
\text { treatment program }\end{array}$ & $5.4(3.9)$ & $6.1(11.4)$ & $9.8(11.0)$ & 0.12 \\
\hline $\begin{array}{l}\text { Proportion of SUD treatment facilities offering } \\
\text { opioid maintenance therapy }\end{array}$ & $18.3(5.3)$ & $17.8(9.8)$ & $20.0(16.2)$ & 0.27 \\
\hline $\begin{array}{l}\text { SUD treatment facilities with opioid treatment } \\
\text { program per } 100 \text { opioid overdose deaths }\end{array}$ & $1.8(0.8)$ & $2.6(3.3)$ & $3.5(1.8)$ & 0.01 \\
\hline $\begin{array}{l}\text { SUD treatment facilities offering opioid } \\
\text { maintenance therapy per } 100 \text { opioid overdose } \\
\text { deaths }\end{array}$ & $5.1(1.0)$ & $6.1(11.2)$ & $8.3(6.6)$ & 0.01 \\
\hline $\begin{array}{l}\text { Waivered buprenorphine prescribers per } 100 \\
\text { opioid overdose deaths }\end{array}$ & $14.8(14.5)$ & $24.5(26.5)$ & $27.8(29.6)$ & 0.17 \\
\hline
\end{tabular}

SUD, substance use disorder

Values in table represent medians (interquartile ranges) unless otherwise noted

*Values are means (standard errors)

†All $P$ values are 2-sided and refer to comparisons between states with any type of work requirement (approved or pending) versus states with no work requirements. P values correspond to Wilcoxon rank sum test, except for "Proportion of SUD treatment facilities accepting Medicaid payments," which compares means using a t test. All analyses include sample of $n=51$ (all US states and District of Columbia)

$\ddagger$ Refers to physicians who have completed Drug Enforcement Administration-required 8-h training course and are authorized to prescribe buprenorphine, a partial opioid agonist, for opioid use disorder 
Given recent work showing that Medicaid work requirements may disproportionately affect individuals with SUD and other behavioral health disorders, ${ }^{5,6}$ states should consider policies that account for the limited availability of SUD treatment to prevent disenrollment and worsening health for individuals with SUD.

Acknowledgments: The authors would like to thank Dr. Lewei (Allison) Lin for guidance on usage of the NSSATS and X-waiver databases. No compensation was received for this contribution.

Corresponding Author: Paul J. Christine, MD, PhD; Department of Internal Medicine, University of Michigan, Ann Arbor, MI, USA (e-mail:pjchris@med.umich.edu).

Author Contributions Drs. Christine and Tipirneni had full access to all of the data in the study and take responsibility for the integrity of the data and the accuracy of the data analysis.

Concept and design: Christine, Tipirneni

Acquisition, analysis, or interpretation of data: Christine, Tipirneni

Drafting of the manuscript: Christine

Critical revision of the manuscript for important intellectual content: Tipirneni

Statistical analysis: Christine

Administrative, technical, or material support: Christine, Tipirneni

Supervision: Tipirneni

Funding Information Dr. Tipirneni is supported by a K08 Clinical Scientist Development Award from the National Institute on Aging (1K08AG056591) and by the University of Michigan Grace H. Elta MD Department of Internal Medicine Early Career Endowment Award.

Data Availability The dataset and statistical code used during the current study are available from the corresponding author on request.

\section{Compliance with Ethical Standards:}

Conflict of Interest: Dr. Tipirneni is on the University of Michigan Institute for Healthcare Policy and Innovation team conducting the evaluation required by the Centers for Medicare and Medicaid Services
(CMS) of the Healthy Michigan Plan (HMP) under contract with the Michigan Department of Health and Human Services (MDHHS). The current work was not conducted as part of this evaluation.

Disclaimer: The views expressed in this paper are those of the authors and do not represent the official views of CMS or MDHHS. The funders supporting the work of Dr. Tipirneni had no role in the design and conduct of the study; collection, management, analysis, and interpretation of the data; preparation, review, or approval of the manuscript; and decision to submit the manuscript for publication.

Publisher's Note: Springer Nature remains neutral with regard to jurisdictional claims in published maps and institutional affiliations.

\section{REFERENCES}

1. Henry $\mathbf{J}$ Kaiser Family Foundation. Medicaid Waiver Tracker: Approved and Pending Section 1115 Waivers by State. https://www.kff.org/medicaid/issue-brief/medicaid-waiver-tracker-approved-and-pending-section1115-waivers-by-state/. Published 2019. Accessed September 19, 2019.

2. National Academy for State Health Policy. A Snapshot of State Proposals to Implement Medicaid Work Requirements Nationwide. https://nashp.org/ state-proposals-for-medicaid-work-and-community-engagement-requirements/. Published 2019. Accessed August 9, 2019.

3. Olfson M, Wall M, Barry CL, Mauro C, Mojtabai R. Impact of Medicaid expansion on coverage and treatment of low-income adults with substance use disorders. Health Aff (Millwood). 2018;37(8):1208-1215. doi:https:// doi.org/10.1377/hlthaff.2018.0124

4. Beetham T, Saloner B, Wakeman SE, Gaye M, Barnett ML. Access to office-based buprenorphine treatment in areas with high rates of opioidrelated mortality: an audit study. Ann Intern Med. 2019;171(1):1-9. doi:https://doi.org/10.7326/M18-3457

5. Wen H, Saloner B, Cummings JR. Behavioral and other chronic conditions among adult Medicaid enrollees: implications for work requirements. Health Aff. 2019;38(4):660-667. doi:https://doi.org/10.1377/ hlthaff.2018.05059

6. Tipirneni R, Patel MR, Goold SD, et al. Association of expanded Medicaid coverage with health and job-related outcomes among enrollees with behavioral health disorders. Psychiatr Serv. 2019:appips201900179. doi:https://doi.org/10.1176/appi.ps.201900179

Publisher's Note Springer Nature remains neutral with regard to jurisdictional claims in published maps and institutional affiliations. 